\title{
Enhancement of Voltage Profile by Optimal Placement of Distributed Generators with UPFC in Distribution Networks
}

\author{
Rudresh B. Magadum, D.B.Kulkarni
}

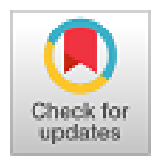

\begin{abstract}
The Distributed generation and fast operating power electronic devices are attracting more attention due to their effective solution for improvement in the voltage profile, to meet the increasing power consumption, reduction in the power loss, enhancement in the power transfer capacity of the transmission lines, reducing the overloading of the entire network. The optimal placement of DG and FACTs devices plays key role in improvement of the network reliability and voltage stability. In this paper exhaustive load flow analysis is carried out for optimal placement of DG and UPFC. The proposed method is tested on 40 bus distribution network. The obtained results are satisfactory in terms of improvement in the overall performance of the distribution network.

Index Terms: Distributed generators; voltage profile; unified power flow controller; power loss; distribution network; reliability; exhaustive load flow analysis; transmission capacity.
\end{abstract}

\begin{tabular}{|c|c|}
\hline \multicolumn{2}{|c|}{ Nomenclature: } \\
\hline DG & Distributed generation \\
\hline UPFC & Unified Power Flow Controller \\
\hline$P_{\text {Loss }}$ & Total power loss in the network \\
\hline $\mathrm{N}$ & Number of transmission lines \\
\hline Gk & $\begin{array}{l}\text { Conductance of } \mathrm{k}^{\text {th }} \text { node connects between nodes } \mathrm{m} \\
\text { and } \mathrm{n} \text {. }\end{array}$ \\
\hline$\delta \mathrm{m}, \delta \mathrm{n}$ & Voltage angle magnitudes at nodes $\mathrm{m}$ and $\mathrm{n}$ \\
\hline SVC & Static Var Compensator \\
\hline FKBC & Fuzzy Knowledge based controller \\
\hline $\mathrm{R}_{\mathrm{n}}$ & Resistance of the $\mathrm{n}^{\text {th }}$ branch \\
\hline $\mathrm{V}_{\max }$ & Maximum Voltage \\
\hline UPQC & Unified Power Quality Conditioner \\
\hline TCSC & Thyristor Controlled static Compensator \\
\hline$I_{n}$ & Current flowing in the branch $\mathrm{n}$ \\
\hline Vm, Vn & Voltage magnitudes at bus $\mathrm{m}$ and $\mathrm{n}$ \\
\hline RDS & Radial Distribution Systems \\
\hline $\mathrm{V}_{\min }$ & Minimum Voltage \\
\hline $\mathrm{k}, \mathrm{m}, \mathrm{n}$ & Nodes \\
\hline FACTS & Flexible AC Transmission Systems \\
\hline MW & Mega watts \\
\hline SSSC & Static Synchronous Series Compensator \\
\hline LFA & Load Flow Analysis \\
\hline
\end{tabular}

Revised Manuscript Received on August 30, 2019.

* Correspondence Author

Rudresh. B. Magadum*, Research Scholar, Department of Electrical and Electronics Engineering, KLS Gogte Institute of Technology, Belagavi, Karnataka, India.

Dr. D.B.Kulkarni, Professor, Department of Electrical and Electronics Engineering, KLS Gogte Institute of Technology, Belagavi, Karnataka, India.

(C) The Authors. Published by Blue Eyes Intelligence Engineering and Sciences Publication (BEIESP). This is an open access article under the CC BY-NC-ND license (http://creativecommons.org/licenses/by-nc-nd/4.0/)

\section{INTRODUCTION}

Now a day's electricity is also acting as a one of the basic need in the modern life. Every year 8-12\% increased in the power consumption makes over loading of the generation, transmission and distribution [1-4]. With expansion of power system network also creates some issues like over loading of line. Droop in the voltage profile, transient instability, line outages, more power losses etc [5-7]. Although old electrical infrastructure makes weak electrical network, with small disturbance may leads to failure of the entire grid. Because of these reasons, power system is gaining more attention for new innovations to address these issues [8-11].

Many researchers are working in different angles to address these issues by incorporating new controlling mechanisms, installing fast operating efficient devices, upgradation of network, interconnecting potential available sources etc [12-15].

In this paper on site power generation with UPFC is used to improve the voltage followed by power loss reduction. Generating $20-25 \%$ of the existing power close to the load centers reduces the over loading of the network. Connecting optimal size with desirable location of DG makes enhancement in the voltage profile reducing current in the network i.e., reducing the $\mathrm{I}^{2} \mathrm{R}$ losses. Installation of UPFC also boosts the voltage profile and helps to monitor the power flow in the network. The combination of both UPFC and DG will helps to increase the overall efficiency of the network. The 40 bus distribution network is chosen as test network. The obtained results are better in terms of efficient, stable and reliable operation of the network.

\section{ORGANIZATION OF THE PAPER}

Section III discusses the methodology. Section IV introduces the simulation results and discussions. Section V discusses the conclusion.

\section{METHODOLOGY}

The main objectives of DG and UPFC placement are maximization of the voltage profile with power loss reduction. The power loss in the network is given by,

$$
\begin{aligned}
& \operatorname{Min}\left\{\mathrm{P}_{\mathrm{Loss}}\right\}= \\
& \operatorname{Min}\left\{\sum_{k=1}^{N}\left(V m^{2}+V n^{2}-2 V m * V n * \cos (8 \mathrm{~m}-\delta \mathrm{n})\right\}\right.
\end{aligned}
$$




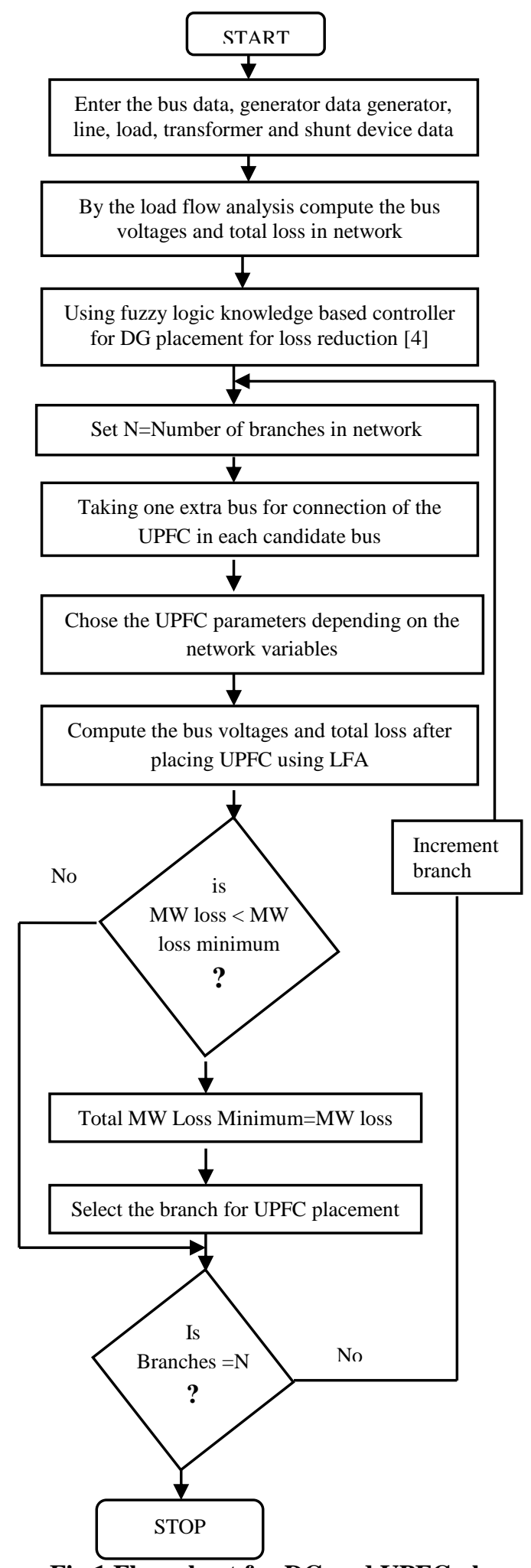

Fig.1 Flow chart for DG and UPFC placement

Fig. 1 shows the flow of optimal placement of DG and UPFC placement for power loss reduction with improvement of the voltage stability.

\section{RESULTS AND DISCUSSIONS}

For DG placement fuzzy knowledge based controller is used. The 40 bus system consists of two generators placed at bus 24 and 40 with 1.0 p.u. specified voltage and also it is connected with14 transformers, 27 transmission lines and total 19 loads are connected across the network with total load of $25.89 \mathrm{MW}$ of active power and 5.9MVar of reactive power. The LFA is carried out using MiPower software. The single line diagram of 40 bus system is as shown in the Fig.1.The system is converged in four iterations with tolerance of 0.001.The LFA results in terms of line flows with line losses and transformer flow and transformer losses are as shown in the Table. 1 and Table 2 respectively.

Table.1 Line flows and line losses

\begin{tabular}{|c|c|c|c|c|c|}
\hline & & \multicolumn{2}{|l|}{ Forward power flow } & \multicolumn{2}{|c|}{ Power loss } \\
\cline { 3 - 6 } $\begin{array}{c}\text { From } \\
\text { bus }\end{array}$ & $\begin{array}{c}\text { To } \\
\text { bus }\end{array}$ & $\begin{array}{c}\text { Real } \\
\text { Power } \\
\text { in MW }\end{array}$ & $\begin{array}{c}\text { Reactive } \\
\text { Power in } \\
\text { MVar }\end{array}$ & $\begin{array}{c}\text { Real } \\
\text { Power } \\
\text { in MW }\end{array}$ & $\begin{array}{c}\text { Reactive } \\
\text { Power in } \\
\text { MVar }\end{array}$ \\
\hline 3 & 9 & 2.444 & 1.454 & 0.0039 & 0.0014 \\
\hline 3 & 5 & 1.519 & 0.975 & 0.0025 & 0.0003 \\
\hline 3 & 26 & 1.100 & 0.604 & 0.0025 & 0.0003 \\
\hline 3 & 6 & 4.544 & 3.059 & 0.0085 & 0.0037 \\
\hline 4 & 15 & 3.251 & 2.133 & 0.0131 & 0.004 \\
\hline 4 & 7 & 3.373 & 2.678 & 0.0041 & 0.0018 \\
\hline 4 & 8 & 7.207 & -5.392 & 0.0066 & 0.0083 \\
\hline 4 & 24 & -5.781 & 1.812 & 0.0378 & 0.024 \\
\hline 9 & 25 & 1.103 & 0.499 & 0.0064 & 0.0008 \\
\hline 9 & 12 & 1.337 & 0.954 & 0.0011 & 0.0001 \\
\hline 10 & 13 & 1.336 & 0.945 & 0.0012 & 0.0002 \\
\hline 10 & 27 & -1.336 & -0.945 & 0.0028 & 0.0004 \\
\hline 6 & 14 & 3.273 & 2.159 & 0.032 & 0.0098 \\
\hline 7 & 27 & 2.761 & 2.231 & 0.0055 & 0.002 \\
\hline 7 & 16 & 0.607 & 0.445 & 0.0015 & 0.0002 \\
\hline 17 & 22 & 0.120 & 0.070 & 0.0001 & 0.0001 \\
\hline 18 & 23 & 0.120 & 0.070 & 0.0001 & 0.0001 \\
\hline 24 & 31 & 1.821 & 1.319 & 0.0038 & 0.0005 \\
\hline 24 & 32 & 0.86 & 0.562 & 0.0011 & 0.0001 \\
\hline 28 & 38 & 0.068 & -0.184 & 0.0001 & 0.0001 \\
\hline 28 & 33 & 0.25 & 0.15 & 0.0003 & 0.0002 \\
\hline 29 & 38 & 0.058 & -0.083 & 0.0001 & 0.0000 \\
\hline 29 & 34 & 0.10 & 0.05 & 0.0001 & 0.0000 \\
\hline 30 & 38 & 0.376 & 0.518 & 0.0015 & 0.0014 \\
\hline 30 & 35 & 0.25 & 0.15 & 0.0003 & 0.0002 \\
\hline 40 & 1 & 9.723 & 6.84 & 0.0214 & -0.0092 \\
\hline 40 & 2 & 8.105 & 1.564 & 0.0103 & -0.031 \\
\hline & & & & & \\
\hline
\end{tabular}




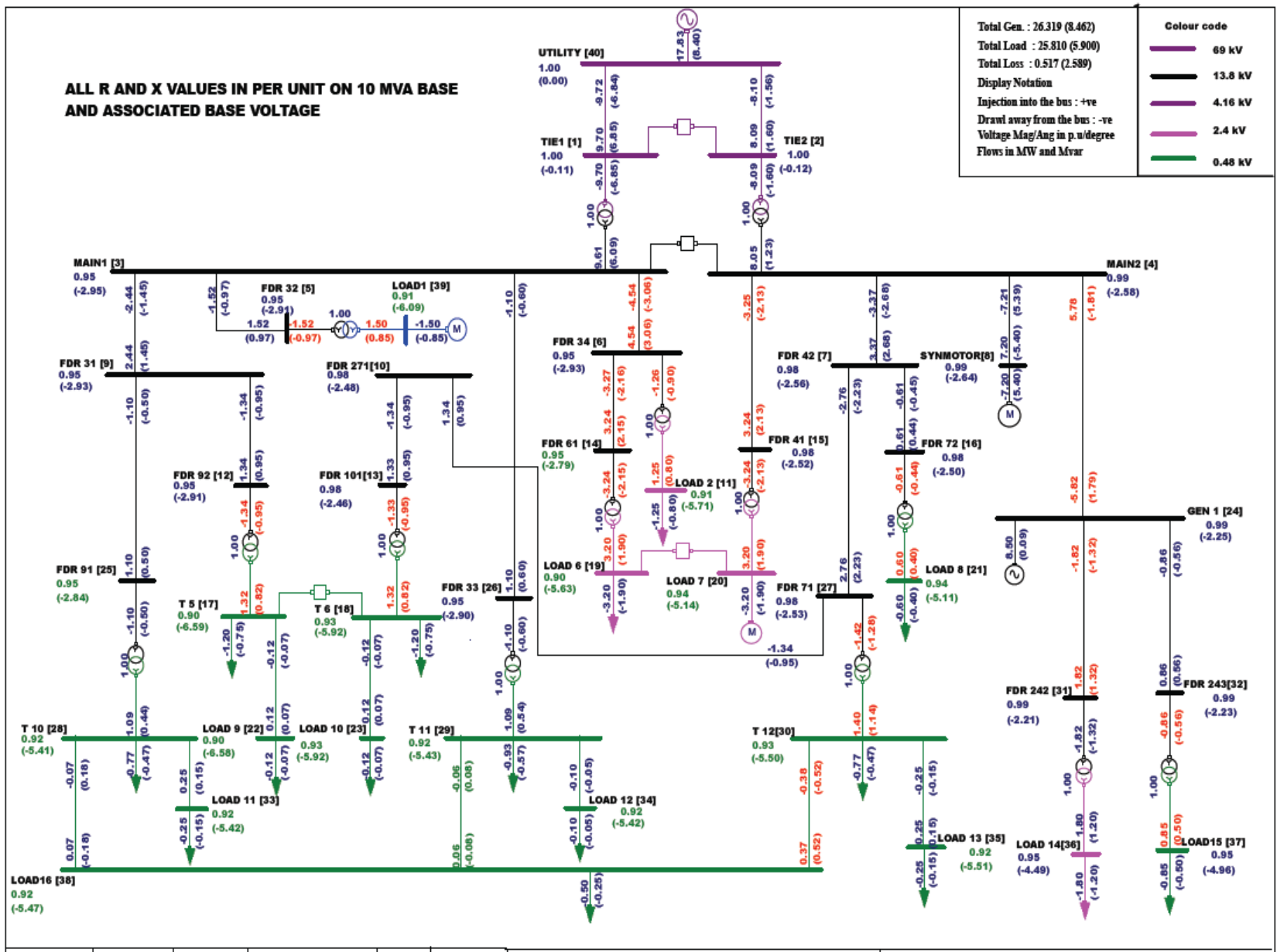

Fig.1 Single line diagram of 40 bus system

Fig.2 shows the voltage magnitude in p.u. at each bus.

Table.2 Transformer power flow and transformer losses

\begin{tabular}{|c|c|c|c|c|c|}
\hline \multirow[b]{2}{*}{$\begin{array}{c}\text { From } \\
\text { bus }\end{array}$} & \multirow[b]{2}{*}{$\begin{array}{l}\text { To } \\
\text { bus }\end{array}$} & \multicolumn{2}{|c|}{$\begin{array}{c}\text { Forward power } \\
\text { flow } \\
\end{array}$} & \multicolumn{2}{|c|}{ Power loss } \\
\hline & & $\begin{array}{c}\text { Real } \\
\text { Power } \\
\text { in } \\
\text { MW }\end{array}$ & $\begin{array}{c}\text { Reactive } \\
\text { Power in } \\
\text { MVar }\end{array}$ & $\begin{array}{c}\text { Real } \\
\text { Power } \\
\text { in MW }\end{array}$ & $\begin{array}{c}\text { Reactive } \\
\text { Power in } \\
\text { MVar }\end{array}$ \\
\hline 1 & 3 & 9.702 & 6.849 & 0.0947 & 0.757 \\
\hline 2 & 4 & 8.094 & 1.595 & 0.0456 & 0.364 \\
\hline 5 & 39 & 1.517 & 0.974 & 0.0166 & 0.1244 \\
\hline 6 & 11 & 1.262 & 0.897 & 0.0121 & 0.0969 \\
\hline 12 & 17 & 1.336 & 0.954 & 0.0157 & 0.1336 \\
\hline 13 & 18 & 1.335 & 0.945 & 0.0147 & 0.1252 \\
\hline 14 & 19 & 3.241 & 2.149 & 0.0413 & 0.2489 \\
\hline 15 & 20 & 3.238 & 2.129 & 0.038 & 0.2289 \\
\hline 16 & 21 & 0.606 & 0.445 & 0.0056 & 0.0449 \\
\hline 25 & 28 & 1.097 & 0.498 & 0.0088 & 0.0618 \\
\hline 26 & 29 & 1.098 & 0.604 & 0.0095 & 0.0662 \\
\hline 27 & 30 & 1.417 & 1.283 & 0.0207 & 0.1449 \\
\hline 31 & 36 & 1.817 & 1.319 & 0.017 & 0.1186 \\
\hline 32 & 37 & 0.859 & 0.562 & 0.0088 & 0.0619 \\
\hline
\end{tabular}

From the LFA analysis it is observed that, minimum voltage in the network is 0.902p.u. at bus 17 and maximum voltage value is 1 p.u. at generators buses i.e., bus 24 and 40.If the voltage profile is low then loads will draws the more reactive power and more power loss will taken placed in terms of $I^{2} \mathrm{R}$.

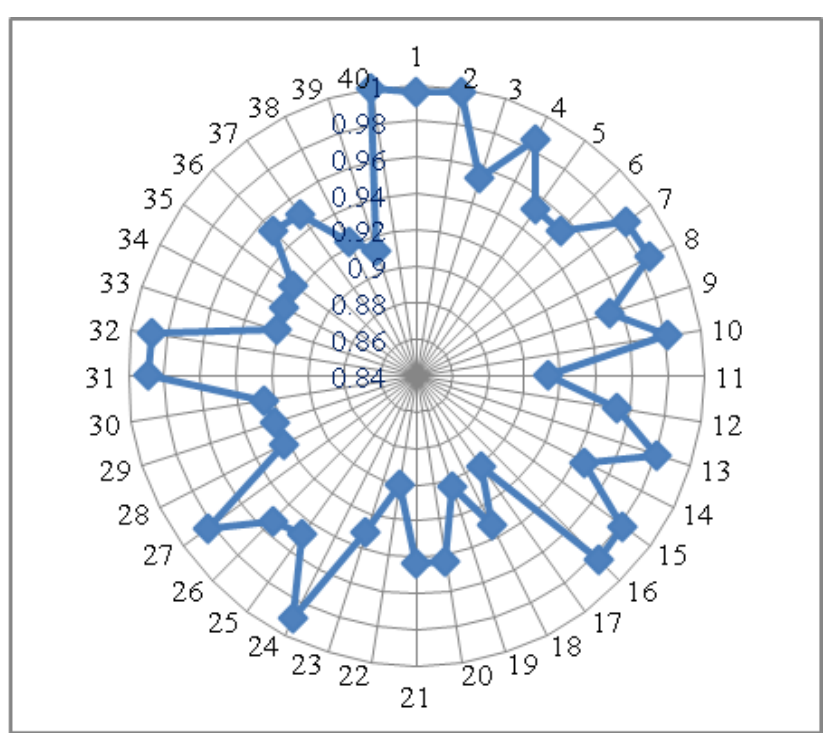

Fig.2 Voltage profile of 40 bus system

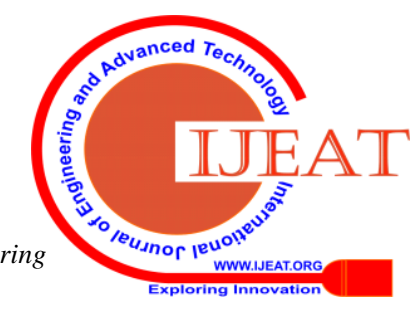


Table.3 Voltage value in p.u in different scenarios

\begin{tabular}{|c|c|c|c|c|}
\hline $\begin{array}{l}\text { Bus } \\
\text { No. }\end{array}$ & $\begin{array}{l}\text { Voltage } \\
\text { in p.u. }\end{array}$ & $\begin{array}{c}\text { After } \\
\text { connecting } \\
\text { DG at bus } \\
5 \\
\end{array}$ & $\begin{array}{l}\text { Connecting } \\
\text { UPFC } \\
\text { between } 6 \\
\text { and } 14 \\
\end{array}$ & $\begin{array}{c}\text { DG } \\
\text { with } \\
\text { UPFC }\end{array}$ \\
\hline 1 & 0.9965 & 0.9968 & 0.9966 & 0.9986 \\
\hline 2 & 0.9983 & 0.9986 & 0.9988 & 0.9995 \\
\hline 3 & 0.9545 & 0.9621 & 0.9556 & 0.9685 \\
\hline 4 & 0.9853 & 0.9862 & 0.9872 & 0.9912 \\
\hline 5 & 0.9533 & 1.0000 & 0.9539 & 1.0000 \\
\hline 6 & 0.9530 & 0.9823 & 0.9581 & 0.9923 \\
\hline 7 & 0.9843 & 0.9852 & 0.9845 & 0.9902 \\
\hline 8 & 0.9852 & 0.9864 & 0.9853 & 0.9881 \\
\hline 9 & 0.9532 & 0.9632 & 0.9534 & 0.9762 \\
\hline 10 & 0.9812 & 0.9824 & 0.9814 & 0.9886 \\
\hline 11 & 0.9134 & 0.9256 & 0.9238 & 0.9345 \\
\hline 12 & 0.9526 & 0.9538 & 0.9624 & 0.9685 \\
\hline 13 & 0.9806 & 0.9825 & 0.9828 & 0.9845 \\
\hline 14 & 0.9452 & 0.9564 & 0.9586 & 0.9614 \\
\hline 15 & 0.9819 & 0.9835 & 86 & 0.9884 \\
\hline 16 & 0.9826 & 0.9834 & 0.9884 & 0.9896 \\
\hline 17 & 0.9020 & 0.9120 & 0.9248 & 0.9312 \\
\hline 18 & 0.9317 & 0.9412 & 0.9416 & 0.9514 \\
\hline 19 & 0.9045 & 0.912 & 0.9213 & 0.9285 \\
\hline 20 & 0.943 & 0.9435 & 0.9445 & 0.9506 \\
\hline 21 & 0.9429 & 0.9534 & 0.9438 & 0.9587 \\
\hline 22 & 0.9010 & 0.9200 & 0.9023 & 0.9289 \\
\hline 23 & 0.9309 & 0.9386 & 0.9352 & 0.9408 \\
\hline 24 & 1.0000 & 1.0000 & 1.0000 & 1.0000 \\
\hline 25 & 0.9483 & 0.9496 & 0.9495 & 0.9587 \\
\hline 26 & 0.9527 & 0.9623 & 0.9581 & 0.9728 \\
\hline 27 & 0.9827 & 0.9828 & 0.985 & 0.9886 \\
\hline 28 & 0.9228 & 0.9345 & 0.9256 & 0.9312 \\
\hline 29 & 0.9231 & 0.9332 & 0.9235 & 0.9412 \\
\hline 30 & 0.9261 & 0.9345 & 0.9268 & 0.9345 \\
\hline 31 & 0.9885 & 0.9894 & 0.9886 & 0.9912 \\
\hline 32 & 0.989 & 0.9892 & 0.9895 & 0.9990 \\
\hline 33 & 0.9216 & 0.9218 & 0.9315 & 0.9338 \\
\hline 34 & 0.9225 & 0.9318 & 0.9321 & 0.9412 \\
\hline 35 & 0.9249 & 0.928 & 0.9312 & 0.9387 \\
\hline 36 & 0.9526 & 0.955 & 0.9628 & 0.9689 \\
\hline 37 & 0.9503 & 0.9526 & 0.9618 & 0.9687 \\
\hline 38 & 0.9231 & 0.9285 & 0.93 .00 & 0.9405 \\
\hline 39 & 0.9118 & 0.9218 & 0.9216 & 0.9312 \\
\hline 40 & 1.0000 & 1.0000 & 1.0000 & 1.0000 \\
\hline
\end{tabular}

Table.3 shows the voltage comparison of different conditions. In base case it is observed that, the minimum voltage 0.9010p.u. at bus number 22 and maximum voltages in the network is 1.0 at generator buses. The analytical method is used for the DG placement considering the acceptable voltage enhancement with power loss minimization. By connecting appropriate size of the DG at bus-5, it is observed 0.912 p.u. as minimum voltage at bus number 22. The voltage profile in the network is improved upto $5-10 \%$.
The UPFC placement also carried out, to verify the effectiveness in the voltage profile by analytical method. It is observed that, line between 6 and 14 is weakest point in the network. Hence it is chosen for the UPFC connection taking bus 41 as a UPFC connecting bus. After connecting UPFC the minimum voltage in the network is $0.9023 p$.u. at bus-22.The combination of DG with UPFC is also tested and it is observed that acceptable improvement in the voltage profile with reduction in the total power loss of the distribution network. Fig.3 shows the voltage comparison of 40 bus distribution network. Four cases are considered here mainly base case with UPFC, with DG and combination of DG-UPFC. In all three cases enhancement of the voltage profile is observed. Connecting combination of DG with UPFC increases overall efficiency of the network with maintaining the voltage stability in the network.

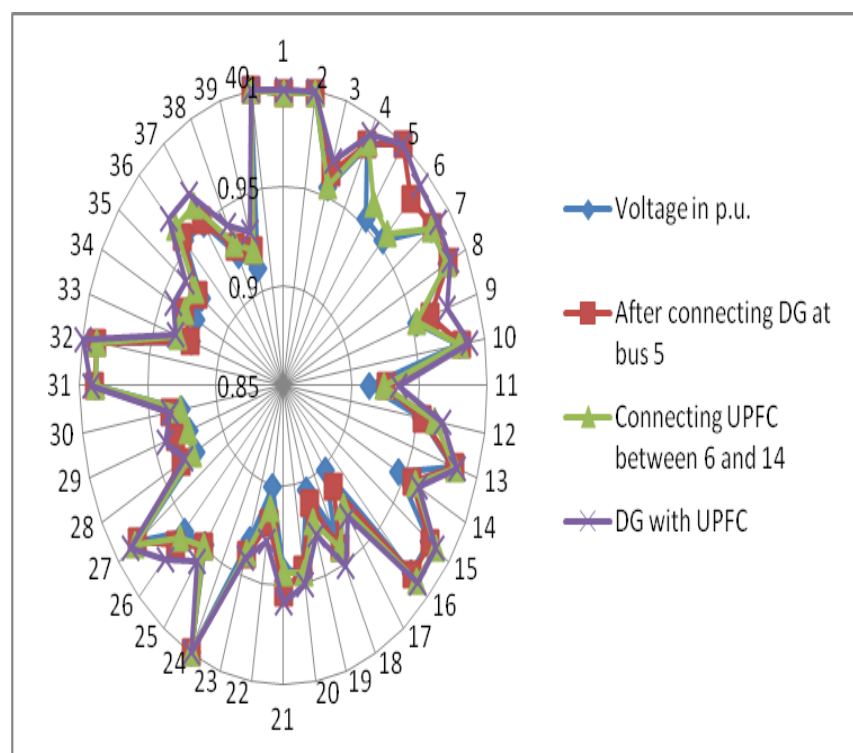

Fig.3 Voltage profile in p.u. base case with DG, UPFC and combination of DG-UPFC

\section{V.CONCLUSION}

In this paper improvement of the voltage profile with total power loss is minimized using optimal placement of DG with UPFC. The MiPower software tool is used for the analysis. The 40 bus distribution network is used as test system. The obtained results are very effective for the stable and healthy and efficient operation of the distribution network.

\section{REFERENCES}

1. K.R.Padiyar, "FACTS controllers in transmission and distribution", New age international publishers, Edition 2007.

2. Singh, Bindeshwar, Payasi, R.P., Shukla, Vipul, "A taxonomical review on impact assessment of optimally placed DGs and FACTS controllers", Energy Rep. 3, 94-108.

3. Duong Quoc Hung, Nadarajah Mithulananthan, R. C. Bansal, "Analytical Expressions for DG Allocation in Primary Distribution Networks", IEEE Transactions on Energy Conversion, Vol. 25, No. 3 , September 2010,pp.814-820.

4. Rudresh B Magadum, Sateesh N Dodamani and D.B.Kulkarni, "Optimal Placement of Unified Power Flow Controller (UPFC) using Fuzzy Logic", IEEE international conference, ICEES 2019.

5. Rudresh B Magadum, D.B.Kulkarni, "Optimal Placement and Sizing of Multiple Distributed Generators using Fuzzy Logic”, IEEE international conference ICEES-2019. 
6. Rudresh.B.Magadum, Dr.D.B.Kulkarni, "Power Loss Reduction by Optimal Location of DG using Fuzzy Logic", IEEE conference ICSTM-2015, pp.338-343.

7. Mostafa F. Shaaban, Yasser M. Atwa, Ehab F. El-Saadany, "DG Allocation for Benefit Maximization in Distribution Networks", IEEE Transactions on Power Systems, Vol. 28, No. 2, May 2013,pp 639-649.

8. Mohammad H. Moradi, Mohamad Abedini, and S. Mahdi Hosseinian, "A Combination of Evolutionary Algorithm and Game Theory for Optimal Location and Operation of DG from DG Owner Standpoints", IEEE Transactions on Smart Grid, Vol. 7, No. 2, March 2016,pp.608-616.

9. Fahad S. Abu-Mouti, M. E. El-Hawary, "Optimal Distributed Generation Allocation and Sizing in Distribution Systems via Artificial Bee Colony Algorithm", IEEE transactions on power delivery, vol. 26, no. 4, october 2011, pp-2090-2101.

10. U.Sultana, AzharB.Khairuddin, M.M.Aman , A.S.Mokhtar, N.Zareen , "A review of optimum DG placement based on minimization of power losses and voltage stability enhancement of distribution system", Renewable and Sustainable Energy Reviews 63(2016)363-378

11. Rudresh B Magadum, D.B.Kulkarni, "Optimal Placement of Distributed Transformer with STATCOM to Enhance the Efficiency of the Distribution Networks", International Journal of Recent Technology and Engineering, Volume-8.Issue-2, pp.3720-3725, July-2019.

12. P.S. Georgilakis, and N.D.Hatziargyriou, Optimal distributed generation placement in power distribution networks: models, methods, and future research. IEEE Transactions on Power Systems, vol. 28, no. 3, pp.3420-3428, 2013.

13. Y. M. Atwa, E. F. El-Saadany, M. M. A. Salama, and R. Seethapathy, "Optimal renewable resources mix for distribution system energy loss minimization,” IEEE Trans. Power Syst., vol. 25, no. 1, pp. 360-370, Feb. 2010

14. Rudresh B Magadum, D.B.Kulkarni, "Optimal Placement of Capacitor to Enhance the Efficiency of the Distribution Network", International Journal of Innovative Technology and Exploring Engineering, Volume-8, Issue-9, pp 2877-2881, July 2019.

15. Stephen W. Fardo Dale R. Patrick, "Electrical Power Systems Technology", Third Edition, published by Fairmont Press, Inc., Taylor and Francis group, 2008

16. Rudresh B Magadum, D.B.Kulkarni, "Energy Loss Minimization by Optimal Siting and Sizing of DG with Network Reconfiguration in Distribution Networks", IJITEE, Volume-8, issue-10,August-2019.

\section{AUTHORS PROFILE}

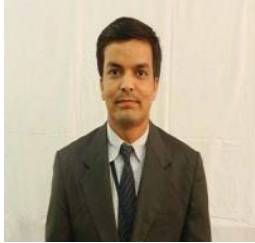

Mr.Rudresh.B.Magadum was born in Sankeshwar, Karnataka, India Jul 09, 1987. He obtained his B.E and M.Tech from VTU Belagavi in 2010 and 2012 respectively. Presently he is pursuing Ph.D at KLS Gogte institute of technology, Belagavi. His area of interests includes distributed generation, micro grid, smart grid, power quality and HVDC.

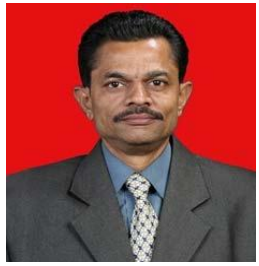

Dr. D.B. Kulkarni was born in Belagavi, Karnataka, India on Feb 10, 1966. He obtained his B.E and M.E degrees from Walchand college of Engineering, Sangli, Maharashtra, India in 1986 and 1993 respectively \& Ph.D in the area of Power quality from VTU, Belagavi in 2012.Currently working as professor in Electrical and Electronics Engineering department, KLS Gogte Institute of Technology, Belagavi. His areas of interest include Power quality, FACTS, HVDC transmission and Power systems.

\section{APPENDIX}

Table.5 Line data

\begin{tabular}{|c|c|c|c|}
\hline From bus & To bus & $\begin{array}{c}\text { Resistance in } \\
\text { p.u. }\end{array}$ & $\begin{array}{c}\text { Reactance in } \\
\text { p.u. }\end{array}$ \\
\hline 3 & 9 & 0.0044 & 0.00161 \\
\hline 3 & 5 & 0.0070 & 0.00091 \\
\hline
\end{tabular}

\begin{tabular}{|c|c|c|c|}
\hline 3 & 26 & 0.0146 & 0.0019 \\
\hline 3 & 6 & 0.00257 & 0.00113 \\
\hline 4 & 15 & 0.00844 & 0.00257 \\
\hline 4 & 7 & 0.00217 & 0.00095 \\
\hline 4 & 8 & 0.00079 & 0.00099 \\
\hline 4 & 24 & 0.0100 & 0.00636 \\
\hline 9 & 25 & 0.0395 & 0.00512 \\
\hline 9 & 12 & 0.00355 & 0.00046 \\
\hline 10 & 13 & 0.00431 & 0.00056 \\
\hline 10 & 27 & 0.0102 & 0.00133 \\
\hline 6 & 14 & 0.0189 & 0.00576 \\
\hline 7 & 27 & 0.00423 & 0.00154 \\
\hline 7 & 16 & 0.0256 & 0.00332 \\
\hline 17 & 22 & 0.0582 & 0.02430 \\
\hline 18 & 23 & 0.0464 & 0.02390 \\
\hline 24 & 31 & 0.00732 & 0.00095 \\
\hline 24 & 32 & 0.0104 & 0.00135 \\
\hline 28 & 38 & 0.0321 & 0.02930 \\
\hline 28 & 33 & 0.0291 & 0.0230 \\
\hline 29 & 38 & 0.0424 & 0.03870 \\
\hline 29 & 34 & 0.0451 & 0.0130 \\
\hline 30 & 38 & 0.0321 & 0.02930 \\
\hline 30 & 35 & 0.0291 & 0.0230 \\
\hline 40 & 1 & 0.0015 & 0.00296 \\
\hline 40 & 2 & 0.0015 & 0.00296 \\
\hline
\end{tabular}

\begin{tabular}{|c|c|c|c|}
\hline \multicolumn{4}{|c|}{ Table.6 Bus data } \\
\hline $\begin{array}{l}\text { BUS } \\
\text { NO. }\end{array}$ & BUS kV & BUS NO. & BUS kV \\
\hline 1 & 69.0 & 21 & 0.48 \\
\hline 2 & 69.0 & 22 & 0.48 \\
\hline 3 & 13.8 & 23 & 0.48 \\
\hline 4 & 13.8 & 24 & 13.8 \\
\hline 5 & 13.8 & 25 & 13.8 \\
\hline 6 & 13.8 & 26 & 13.8 \\
\hline 7 & 13.8 & 27 & 13.8 \\
\hline 8 & 13.8 & 28 & 0.48 \\
\hline 9 & 13.8 & 29 & 0.48 \\
\hline 10 & 13.8 & 30 & 0.48 \\
\hline 11 & 2.40 & 31 & 13.8 \\
\hline 12 & 13.8 & 32 & 13.8 \\
\hline 13 & 13.8 & 33 & 0.48 \\
\hline 14 & 13.8 & 34 & 0.48 \\
\hline 15 & 13.8 & 35 & 0.48 \\
\hline 16 & 13.8 & 36 & 2.40 \\
\hline 17 & 0.48 & 37 & 0.48 \\
\hline 18 & 0.48 & 38 & 0.48 \\
\hline 19 & 2.40 & 39 & 4.16 \\
\hline 20 & 2.40 & 40 & 69.0 \\
\hline
\end{tabular}




\begin{tabular}{|c|c|c|c|}
\hline \multicolumn{4}{|c|}{ Table.7 Load data } \\
\hline Sl.No. & Node & $\begin{array}{l}\text { Real power } \\
\text { in MW }\end{array}$ & $\begin{array}{c}\text { Reactive } \\
\text { power in } \\
\text { MVar }\end{array}$ \\
\hline 1 & 39 & 1.50 & 0.85 \\
\hline 2 & 11 & 1.25 & 0.80 \\
\hline 3 & 8 & 7.20 & -5.40 \\
\hline 4 & 17 & 1.20 & 0.75 \\
\hline 5 & 18 & 1.20 & 0.75 \\
\hline 6 & 19 & 3.20 & 1.90 \\
\hline 7 & 20 & 3.20 & 1.90 \\
\hline 8 & 21 & 0.60 & 0.40 \\
\hline 9 & 22 & 0.12 & 0.07 \\
\hline 10 & 23 & 0.12 & 0.07 \\
\hline 11 & 33 & 0.25 & 0.15 \\
\hline 12 & 34 & 0.10 & 0.05 \\
\hline 13 & 35 & 0.25 & 0.15 \\
\hline 14 & 36 & 1.80 & 1.20 \\
\hline 15 & 37 & 0.85 & 0.50 \\
\hline 16 & 38 & 0.50 & 0.25 \\
\hline 17 & 28 & 0.77 & 0.47 \\
\hline 18 & 29 & 0.93 & 0.57 \\
\hline 19 & 30 & 0.77 & 0.47 \\
\hline
\end{tabular}

\begin{tabular}{|c|c|c|c|c|c|}
\hline \multicolumn{7}{|c|}{ Table.8 Transformer data } \\
\hline $\begin{array}{c}\text { From } \\
\text { Node }\end{array}$ & $\begin{array}{c}\text { To } \\
\text { node }\end{array}$ & R(p.u.) & X(p.u.) & $\begin{array}{c}\text { Nomin } \\
\text { al Tap }\end{array}$ & $\begin{array}{c}\text { MVA } \\
\text { rating }\end{array}$ \\
\hline 1 & 3 & 0.0066 & 0.0533 & 1.00 & 15.0 \\
\hline 2 & 4 & 0.0066 & 0.0533 & 1.00 & 15.0 \\
\hline 5 & 39 & 0.0464 & 0.348 & 1.00 & 1.73 \\
\hline 6 & 11 & 0.0458 & 0.367 & 1.00 & 1.50 \\
\hline 12 & 17 & 0.0529 & 0.450 & 1.00 & 1.50 \\
\hline 13 & 18 & 0.0529 & 0.450 & 1.00 & 1.50 \\
\hline 14 & 19 & 0.0244 & 0.147 & 1.00 & 3.75 \\
\hline 15 & 20 & 0.0244 & 0.147 & 1.00 & 3.75 \\
\hline 16 & 21 & 0.0958 & 0.767 & 1.00 & 0.75 \\
\hline 25 & 28 & 0.0548 & 0.383 & 1.00 & 1.50 \\
\hline 26 & 29 & 0.0548 & 0.383 & 1.00 & 1.50 \\
\hline 27 & 30 & 0.0548 & 0.383 & 1.00 & 1.50 \\
\hline 31 & 36 & 0.0329 & 0.230 & 1.00 & 2.50 \\
\hline 32 & 37 & 0.0821 & 0.575 & 1.00 & 1.00 \\
\hline
\end{tabular}

